\title{
AVALIAÇÃO PRELIMINAR DAS CARACTERÍSTICAS E TENDÊNCIAS DEMOGRÁFICAS DO MUNICÍPIO DE JUIZ DE FORA (MG)
}

Pedro José de Oliveira Machado Prof. do Dep. de Geociências - UFJF

RESUMO: O presente artigo é parte do trabalho sobre população que desenvolvemos para o Plano Diretor do Município de Juiz de Fora. Trata-se de um estudo inicial, no nível de um diagnóstico, sobre as principais características da população do município, sua dinâmica demográfica, seu ritmo de crescimento e o importante papel que a migração assume na composição de sua população total.

Palavras Chaves: dinâmica demográfica, migração.

ABSTRACT: This paper registers part of a research on population, developed for the Municipal Directive Plan of Juiz de Fora. It's a first aproximation, on the level of a diagnosis, informing about the most important features of municipal population, it's demografic dynamic and the important role migration plays on the composition of the whole population.

Key Words: migration, dynamic of the population.

\section{INTRODUÇÃO}

Esse estudo inicial sobre a população de Juiz de Fora tem como objetivo principal melhor conhecer algumas das características e tendências demográficas locais. Para tanto buscou-se, através dos dados do IBGE (Fundação Instituto Brasileiro de Geografia e Estatística), fundamentalmente pelos Censos Demográficos de 1970, 1980 e 1991, analisar alguns parâmetros próprios da dinâmica demográfica de Juiz de Fora, visto que o mais amplo conhecimento da mobilidade espacial da população é um dos elementos mais importantes e mesmo fundamentais no planejamento e na execução de ações que buscam dar a esta mesma população uma melhor "qualidade de vida".
As modificações que vêm se processando no comportamento de sua população, por sexo e por faixas etárias; o importante peso do processo migratório na composição da população total da cidade; a distribuição (e/ou concentração) da população no município; as taxas de crescimento e as projeções para os próximos anos; o papel centralizador regional exercido por Juiz de Fora; a relação entre infra-estrutura urbana básica e crescimento da população e das demandas pelos serviços públicos e, ainda, os índices e indicadores relativos aos domicílios, são alguns dos temas abordados nesse estudo preliminar. 


\section{O CRESCIMENTO DEMOGRÁFICO}

Tabela 1

População Residente (*) do Município de Juiz de Fora, por sexo e grupos etários, nos anos de 1970, 1980 e 1991.

\begin{tabular}{|l|r|r|r|r|r|r|r|r|c|}
\hline & \multicolumn{3}{|c|}{ Censo 1970} & \multicolumn{3}{c|}{ Censo 1980} & \multicolumn{3}{c|}{ Censo 1991} \\
\hline Grupos & Homens & Mulheres & $\%$ & Homens & Mulheres & $\%$ & Homens & Mulheres & $\%$ \\
\hline $00-04$ & 13.637 & 13.448 & 11,36 & 16.358 & 15.670 & 10,41 & 18.213 & 17.674 & 9,30 \\
\hline $05-09$ & 14.930 & 14.843 & 12,48 & 14.181 & 13.908 & 9,13 & 18.013 & 17.728 & 9,26 \\
\hline $10-14$ & 14.570 & 14.781 & 12,31 & 15.808 & 15.918 & 10,31 & 18.884 & 18.208 & 9,61 \\
\hline $15-19$ & 13.505 & 14.631 & 11,80 & 18.028 & 18.586 & 11,90 & 16.090 & 16.910 & 8,55 \\
\hline $20-24$ & 11.298 & 12.710 & 10,07 & 16.853 & 17.845 & 11,28 & 17.205 & 18.390 & 9,22 \\
\hline $25-29$ & 7.668 & 8.973 & 6,97 & 12.981 & 14.314 & 8,87 & 17.555 & 19.263 & 9,53 \\
\hline $30-34$ & 6.951 & 7.792 & 6,18 & 10.417 & 11.517 & 7,13 & 16.299 & 18.186 & 8,94 \\
\hline $35-39$ & 6.398 & 7.348 & 5,76 & 7.968 & 9.250 & 5,59 & 13.638 & 15.613 & 7,58 \\
\hline $40-49$ & 11.047 & 12.664 & 9,94 & 14.182 & 16.054 & 9,83 & 20.059 & 22.889 & 11,12 \\
\hline $50-59$ & 7.796 & 8.380 & 6,78 & 11.050 & 12.910 & 7,79 & 13.445 & 15.848 & 7,58 \\
\hline $69-69$ & 4.346 & 5.038 & 3,93 & 6.748 & 7.932 & 4,77 & 9.401 & 12.408 & 5,66 \\
\hline 70 e mais & 2.165 & 3.081 & 2,19 & 3.631 & 5.300 & 2,90 & 5.583 & 8.494 & 3,65 \\
\hline id.ig. & 251 & 259 & 0,23 & 53 & 63 & 0,09 & & & \\
\hline totais & 114.562 & 123.948 & 100,00 & 148.258 & 159.267 & 100,00 & 184.385 & 201.611 & 100,00 \\
\hline
\end{tabular}

Obs.: 1) id.ig.: idade ignorada

2) Para podermos compatibilizar e comparar os dados de 1970, 1980 e 1991, os grupos etários foram divididos de 5 em 5 anos até os 39 anos de idade. A partir dos 40 anos, os grupos etários passam a formar faixas de 10 anos, pois as informações foram tomadas (e divulgadas) de formas distintas nos vários Censos Demográficos; ( $\left.{ }^{*}\right)$ O IBGE ("Fundação Instituto Brasileiro de Geografia e Estatística"), nos Censos Demográficos que realiza, coleta informações sobre as pessoas presentes (moradoras ou não no domicílio) e sobre os moradores ausentes dos seus domicílios por período não superior a 12 meses, na data do Censo. Resulta deste procedimento, a classificação da população total em : "População Residente" ou "População de Direito", constituída pelas pessoas moradoras no domicílio, mesmo que ausentes na data do Censo ; e "População Presente" ou "População de Fato", aquela formada pelas pessoas presentes no domicílio;

Fonte: FIBGE (1973: 57/61) ; FIBGE (1982: 184/185) ; FIBGE (1991: 81, 149, 216)

Com base nos dados anteriores, nas informações contidas na tabela $n .^{\circ} 01$, que mostra a evolução da população de Juiz de Fora, por sexo e faixa etária, no período de 1970 a 1991, é possível fazer-se, dentre outras, algumas considerações sobre o ritmo e sobre as características do crescimento demográfico desse município.

Os dados apontam para um decréscimo da Taxa de Natalidade nessas últimas décadas, uma vez que a contribuição percentual dos primeiros grupos etários, de zero a 24 anos ("população jovem"), e especialmente, de zero a 4 anos, mostrou freqüente tendência de declínio em relação ao total da população. Os grupos etários posteriores (de 25 a 49 anos), por outro lado, mostram um constante aumento da sua participação relativa no conjunto total da população. O índice "vacila" (é mais ou menos estável) no grupo etário de 50 a 59 anos e coloca-se a aumentar, progressivamente, em todos os Censos, nas últimas faixas etárias. 
Das várias reflexões que podem ser feitas a partir dessas situações, algumas parecem bem cristalinas: desaceleração do número de nascimentos (com sensível diminuição da taxa de natalidade), ou seja, as famílias ficaram menores e a proporção número de filhos/mulher caiu igualmente; de outro lado, o número de habitantes com mais de 60 anos de idade aumentou constantemente em todos os Censos, mostrando que a população de Juiz de Fora vem passando por um visível processo de "envelhecimento".

A faixa etária que reúne a população de 25 a 34 anos mostrou, da mesma forma, um ritmo crescente de participação relativa no total da população. Idade "produtiva" (economicamente), seja para trabalho ou para estudo, esse grupo teve seu crescimento certamente impactado pelos valores da migração, principalmente das populações da região de influência direta de Juiz de Fora, que buscam "melhores oportunidades" nesse pólo regional.

Como causas da sensível diminuição da taxa de crescimento demográfico de Juiz de Fora podem ser citadas, além de outras, as reduções nas taxas de Crescimento Vegetativo (dados da tabela n.․ 01) e no saldo final das migrações, não por uma redução substancial dos que "chegam" (imigrantes), que pelo contrário representam importante elemento no crescimento da população local, mas muito provavelmente por uma contribuição maior dos que "saem" (emigrantes). Quanto aos efeitos diretos dessa situação, o mais sensível aspecto talvez seja o maior e mais rápido envelhecimento da população.

Quanto à composição da população por sexo, cabe uma observação específica e bastante "curiosa". Têm-se duas considerações, um tanto paradoxais, a se fazer: de um lado, a população feminina, que no total é maior que a masculina, não obstante, de outro lado, ocorram mais nascimentos de homens do que de mulheres. Esses dados podem ser comprovados pela tabela $n .^{\circ} 01 \mathrm{e}$ pelo desenho representativo da pirâmide etária de Juiz de Fora/1991, que mostram uma população feminina maior no conjunto total e uma população masculina maior nos grupos etários básicos, de zero a 9 anos. As prováveis causas dessa inversão nos dados têm suas raízes lançadas nos fenômenos associados à migração. As alterações de tendência ocorrem fundamentalmente na idade adulta (basicamente, acima dos 15 anos de idade) e, aí, duas considerações podem ser feitas concomitantemente: uma maior imigração feminina acentuada por uma maior emigração masculina. Os dados dos Censos de 1970 e 1980 (tabelas n.․ 06, a e b, 8 e 9) comprovam que Juiz de Fora recebe, por migração definitiva, muito mais mulheres do que homens. Ao contrário, mesmo que sem contar com dados oficiais, tem-se provavelmente uma maior emigração (saída) masculina nessa mesma idade "produtiva", fato observável pelos dados quantitativos dos grupos etários de 15 a 49 anos, principalmente, e que apontam para uma possível busca de melhores oportunidades profissionais noutros centros. Nos grupos etários mais avançados ( 60 anos e mais), o que se observa é a tendência geral de a mulher viver mais tempo que o homem (maior esperança de vida). Resumidamente, tem-se um número maior de nascimentos masculinos e uma população feminina maior. A explicação dessa situação não deve ser buscada somente nos valores das taxas de mortalidade, diferentes para homens e mulheres, mas sobretudo na importante contribuição das taxas de emigração/ imigração, muito representativas na explicação do crescimento demográfico da cidade, principalmente pela maior imigração feminina.

O formato apresentado pela pirâmide etária de Juiz de Fora - Censo de 1991 concorda e justifica as afirmativas anteriores. Pode-se notar uma "base" masculina e uma alteração dessa situação após os 15 anos de idade. No topo, a pirâmide mostra a maior esperança de vida feminina. Na parte central da pirâmide, a revelação de um desenho 
disforme aponta para a migração como causa dos "desequilíbrios" quantitativos entre os sexos. Há, por certo, um aumento tanto de homens quanto de mulheres, certamente imigrantes - como pode ser comprovado pelos dados específicos sobre migração - porém, o aumento da população feminina é muito mais notável e expressivo, o que também vai afetar as características etárias na parte superior da pirâmide. Essa situação mostra (e confirma) a função pólo-atratora desenvolvida por Juiz de Fora, mas, por outro lado, revela uma outra realidade: além de receber mais mulheres (como comprovam os dados oficiais) como imigrantes, a cidade perde mais homens como emigrantes, o que representará, como pode ser

Tabela 2

População Residente de Juiz de Fora, segundo o Censo Demográfico do IBGE de 1991: Grupos etários e situação por sexo.

\begin{tabular}{|c|c|c|c|}
\hline Grupos etários & Homens & Mulheres & Totais \\
\hline $00-04$ & 18.213 & 17.674 & 35.887 \\
\hline $05-09$ & 18.013 & 17.728 & 35.741 \\
\hline $10-14$ & 18.884 & 18.208 & 37.092 \\
\hline $15-19$ & 16.090 & 16.910 & 33.000 \\
\hline $20-24$ & 17.205 & 18.390 & 35.595 \\
\hline $25-29$ & 17.555 & 19.263 & 36.818 \\
\hline $30-34$ & 16.299 & 18.186 & 34.485 \\
\hline $35-39$ & 13.638 & 15.613 & 29.251 \\
\hline $40-44$ & 11.614 & 13.034 & 24.648 \\
\hline $45-49$ & 8.445 & 9.855 & 18.300 \\
\hline $50-54$ & 7.338 & 8.393 & 15.731 \\
\hline $55-59$ & 6.107 & 7.455 & 13.562 \\
\hline $60-64$ & 5.424 & 7.131 & 12.555 \\
\hline $65-69$ & 3.977 & 5.277 & 9.254 \\
\hline $70-74$ & 2.676 & 3.642 & 6.318 \\
\hline $75-79$ & 1.626 & 2.502 & 4.128 \\
\hline 80 e mais & 1.281 & 2.350 & 3.631 \\
\hline Totais & 184.385 & 201.611 & 385.996 \\
\hline
\end{tabular}

Fonte : FIBGE $(1991: 81,149,216)$ visto, uma população feminina maior justamente a partir dos 15 anos de idade e uma concentração dessa diferença na idade "produtiva" (de 20 a 49 anos). Essa tendência histórica de maior fluxo migratório feminino para a cidade poderá ser profundamente alterada nos próximos anos, tendo em vista a instalação da Mercedes Benz na cidade (e todo o seu rol de empresas satélites), que poderá (e deverá) servir não só de atrativo maior a uma população tipicamente masculina, mas também, de outro lado, poderá reduzir sensivelmente a sua emigração. Esses são dados importantes que deverão trazer, por sua vez, importantes alterações na composição da população total de Juiz de Fora. Tais tendências

\section{Tabela 3}

População Residente do município de Juiz de Fora, urbana e rural e por Distritos.

\begin{tabular}{|l|r|r|r|r|}
\hline $\begin{array}{l}\text { Unidades } \\
\text { Administrativas }\end{array}$ & Censo 1980 & $\%$ & Censo 1991 & \multicolumn{1}{c|}{$\%$} \\
\hline Juiz de Fora (Munic.) & 307.525 & 100,0 & 385.996 & 100,0 \\
\hline urbana & 301.685 & 98,1 & 380.249 & 98,5 \\
\hline rural & 5.840 & 1,9 & 5.747 & 1,5 \\
\hline Distrito Sede & 301.545 & 100,0 & 379.973 & 100,0 \\
\hline urbana & 299.432 & 99,3 & 377.790 & 99,4 \\
\hline rural & 2.113 & 0,7 & 2.183 & 0,6 \\
\hline Sarandira & 1.216 & 100,0 & 1.025 & 100,0 \\
\hline urbana & 685 & 56,3 & 522 & 50,9 \\
\hline rural & 531 & 43,7 & 503 & 49,1 \\
\hline Torreões & 2.588 & 100,0 & 2.748 & 100,0 \\
\hline urbana & 611 & 23,6 & 739 & 26,9 \\
\hline rural & 1.977 & 76,4 & 2.009 & 73,1 \\
\hline Rosário de Minas & 2.176 & 100,0 & 2.250 & 100,0 \\
\hline urbana & 957 & 43,9 & 1.198 & 53,2 \\
\hline rural & 1.219 & 56,1 & 1.052 & 46,8 \\
\hline
\end{tabular}

Fonte : FIBGE (1982: 46, 47) ; FIBGE (1991: 284) 


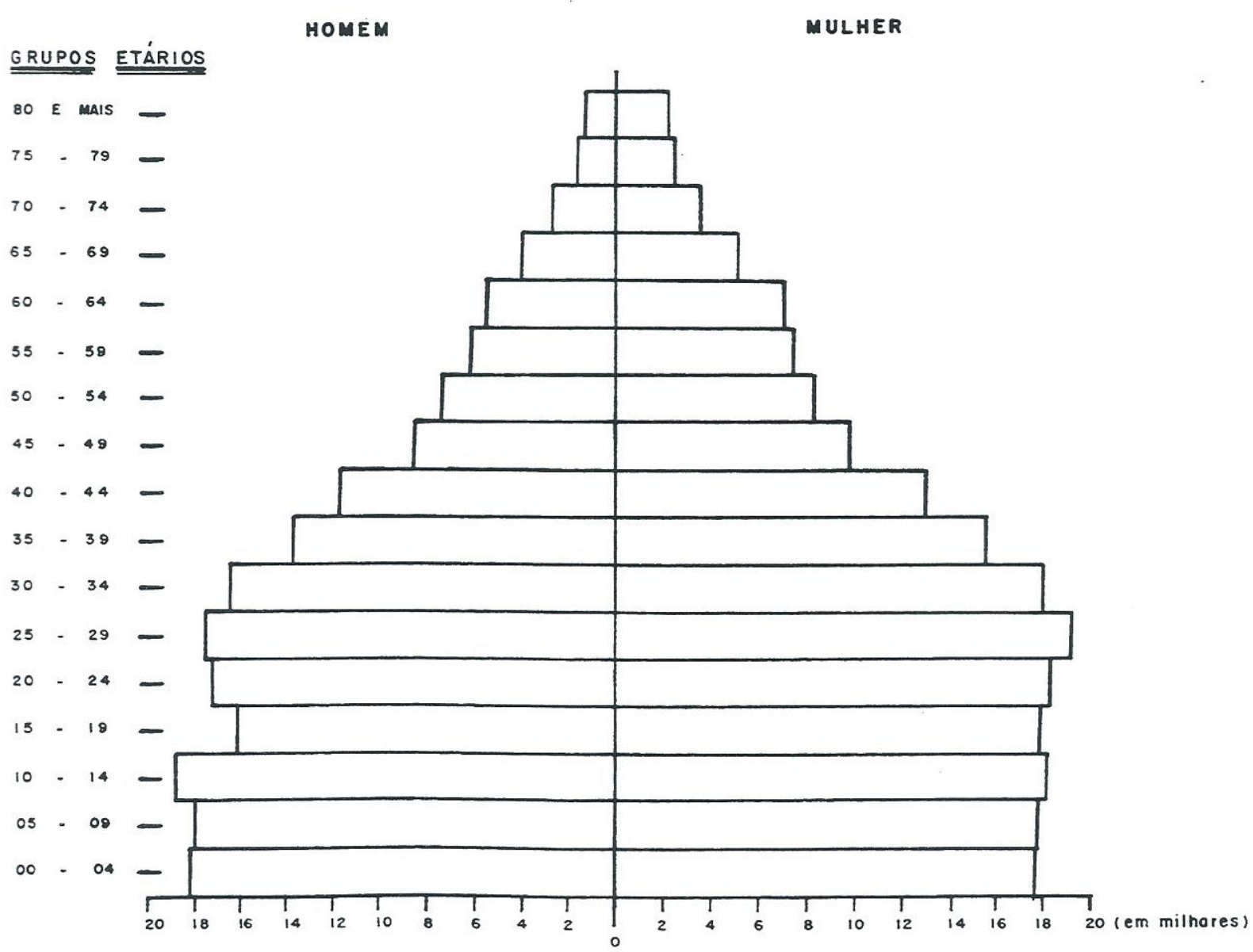

Fig. 1 - Pirâmide etária de Juiz de Fora - Censo Demográfico 1991

(ou hipóteses) poderão ser verificadas quando da realização do próximo Censo Demográfico do ano 2.000, que permitirá a comparação de seus resultados com os de 1991.

$$
\text { É de se destacar, pois, o papel }
$$
importantíssimo que a migração desempenha na composição da população total de Juiz de Fora. Embora ocorresse nos últimos anos, como analisado, emigração masculina e diminuição da taxa de natalidade, deve ser notado que o saldo migratório (imigração emigração) continuou positivo, e isso vem, já há algum tempo, mantendo boa parte do crescimento demográfico local, "compensando" as reduções na taxa de natalidade e a diminuição no tamanho médio das famílias. 
Tabela 4

Densidade Demográfica e Taxa de urbanização de Juiz de Fora no período de 1960 a 1991

\begin{tabular}{|l|c|c|c|c|}
\hline Índices & 1960 & 1970 & 1980 & 1991 \\
\hline Densidade Demográfica & $\left.\mathbf{( *}^{*}\right)$ & 167,5 & 215,9 & 271,1 \\
\hline Taxa de urbanização & 74,46 & 92,37 & 98,10 & 98,51 \\
\hline
\end{tabular}

Obs.: (*) Os dados relativos à Densidade Demográfica para o ano de 1960 não foram considerados, pois a composição territorial do município, à época, era diferente da atual;

Os dados de Densidade Demográfica expressam a unidade Habitantes/Km2 e a Taxa de Urbanização expressa dados percentuais (\%).

Tabela 5

População Residente de Juiz de Fora, por sexo e por Distritos

\begin{tabular}{|l|r|r|r|r|r|r|}
\hline & \multicolumn{3}{|c|}{ Censo Demográfico 1980} & \multicolumn{3}{c|}{ Censo Demográfico 1991} \\
\hline Unidades & \multicolumn{1}{|c|}{ Total } & \multicolumn{1}{c|}{ Homens } & Mulheres & \multicolumn{1}{c|}{ Total } & Homens & \multicolumn{1}{c|}{ Mulheres } \\
\hline Juiz de Fora (Município) & 307.525 & 148.258 & 159.267 & 385.996 & 184.385 & 201.611 \\
\hline Distrito Sede & 301.545 & 145.027 & 156.518 & 379.973 & 181.217 & 198.756 \\
\hline Sarandira & 1.216 & 645 & 571 & 1.025 & 538 & 487 \\
\hline Torreões & 2.588 & 1.428 & 1.160 & 2.748 & 1.454 & 1.294 \\
\hline Rosário de Minas & 2.176 & 1.158 & 1.018 & 2.250 & 1.176 & 1.074 \\
\hline
\end{tabular}

Fonte : FIBGE (1982: 46, 47) ; FIBGE (1991: 81)

Os dados apresentados nas tabelas anteriores revelam duas tendências "históricas", hoje fortemente consolidadas em Juiz de Fora: a concentração da população no Distrito Sede e a forte concentração urbana da quase totalidade da população municipal.

De um lado, tem-se o declínio das atividades econômicas primárias no município (agricultura e pecuária), que ao longo das últimas décadas levou ao grande abandono das áreas rurais e ao forte êxodo em direção à cidade. Paralelamente, a economia do município tomou um "norte" especificamente urbano-industrial, o que tornou Juiz de Fora um pólo de atividades econômicas secundárias e terciárias - tipicamente urbanas - atraindo para seu "centro" não só a sua população rural (e de seus Distritos), mas despertando também as populações das cidades menores sob sua influência. De outro lado, também deve ser destacado que "população urbana" é, por classificação adotada nos Censos do IBGE, aquela que reside na área urbana do município (não levando em consideração, pois, o "modo de vida", mas o local de assentamento). Esse aspecto assume particular importância no caso específico de Juiz de Fora, uma vez que a Área Urbana do município, definida legalmente por seu Perímetro Urbano (Lei Municipal n. $6.910 /$ 86 e Decreto Municipal n. $4.047 / 88$ ), é muito grande, contando cerca de 403 Kmý - pouco menos de 1/3 da área total do município e bem superior ao tamanho da maior parte dos municípios que compõem a sua microregião.

Nota-se que, à exceção do Distrito Sede, a população total dos demais Distritos, quando não diminuiu (como ocorreu com Sarandira, no período 1970/1980 e 1980/ 1991), tendeu a crescer de maneira lenta e tímida, como ocorreu com Rosário de Minas e Torreões no período 1980/1991, após passarem por um declínio populacional na década anterior (1970/1980). 


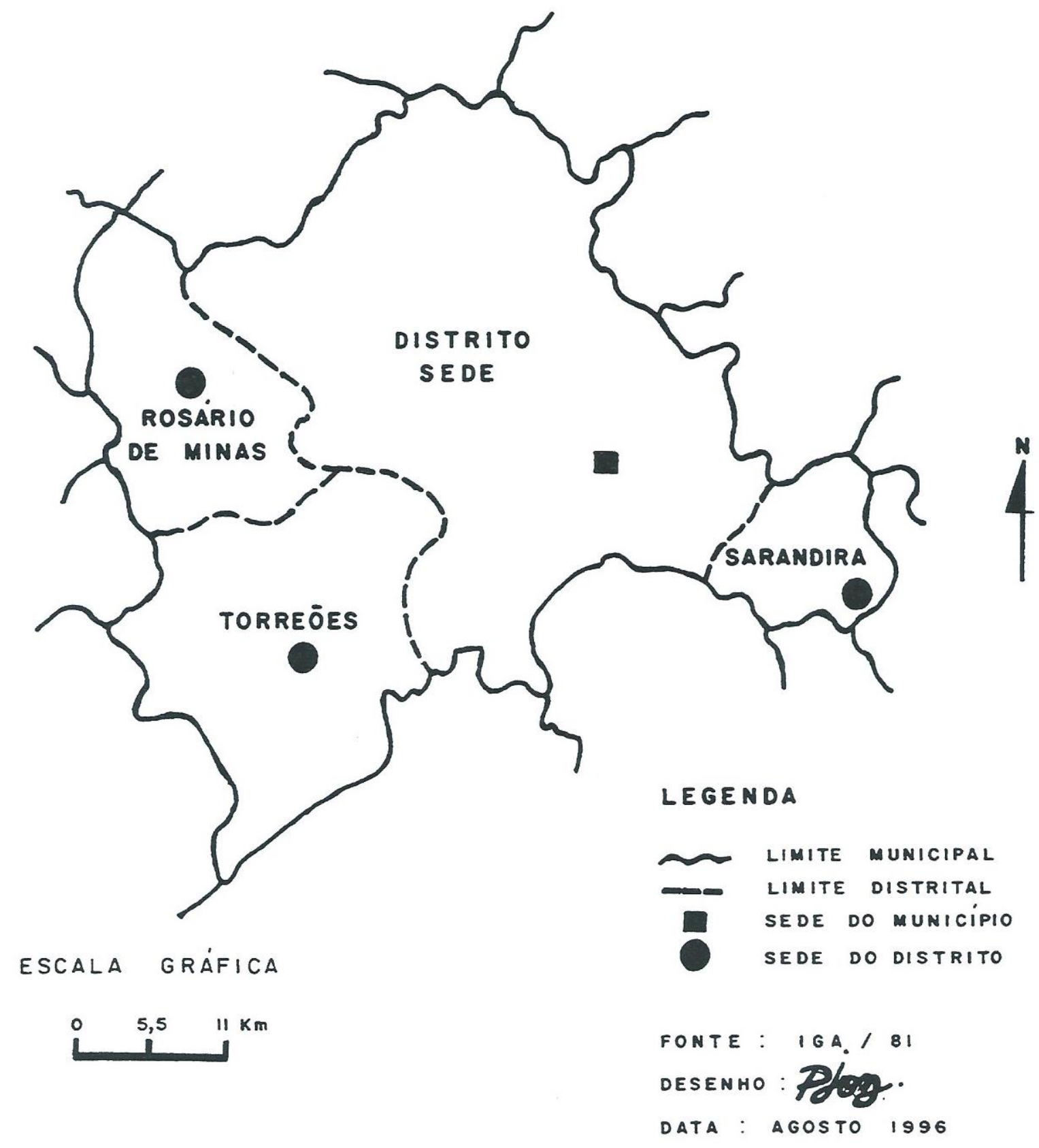

Fig. 2 - Juiz de Fora: Divisão Político-Administrativa

O predomínio da população masculina nesses Distritos é reflexo não só do desenvolvimento de atividades econômicas primárias, historicamente mais ligadas ao homem, mas também (provavelmente) da maior emigração feminina para a "cidade" (em geral, para complementação de estudos ou como mão-de-obra não qualificada).

\section{A PARTICIPAÇÃO DA MIGRAÇÃO NO CRESCIMENTO DEMOGRÁFICO}

Ao estudarmos o crescimento demográfico das populações de um dado lugar, devemos distinguir, sempre que possível, as variações provocadas pelo Crescimento Vegetativo (resultado da diferença entre o 
número de nascimentos e o de óbitos, ou seja, Taxa de Natalidade menos Taxa de Mortalidade), daquelas provocadas pelos movimentos migratórios (transferências definitivas de populações de um lugar para outro).

No caso específico de Juiz de Fora, essa última variável - a migração - assume um papel importantíssimo na explicação e compreensão do crescimento demográfico da cidade. É o saldo imigração/emigração que vem historicamente nutrindo o crescimento demográfico local, como pode ser observado pelos dados contidos nas tabelas que se seguem. Entre 1960 e 1970, por exemplo, de um aumento total da população de 69.015 habitantes, pouco mais de $60 \%$ foram causados pelo processo migratório. Entre 1970 e 1980 , quase $3 / 4$ do incremento demográfico total do município ocorreu em função das migrações (Tabela n.ำ06b).

As tabelas a seguir reúnem importantes informações sobre as características do processo migratório regional, que são uma fonte indispensável a ser considerada no entendimento da dinâmica do crescimento demográfico de Juiz de Fora. Realmente lamentável que muitos dados do Censo Demográfico de 1991 ainda não tenham sido divulgados. Certamente o uso desses dados e a possibilidade de comparação com os dados dos Censos Demográficos de 1970 e 1980 em muito complementariam as presentes análises.

Tabela $6 a$

Juiz de Fora : incremento demográfico e migração

\begin{tabular}{|l|c|c|c|c|c|c|c|c|c|c|c|}
\hline & \multicolumn{2}{|c|}{$\begin{array}{c}\text { População } \\
\text { Residente }\end{array}$} & \multicolumn{2}{c|}{$\begin{array}{c}\text { Naturais do } \\
\text { Municipio }\end{array}$} & \multicolumn{2}{c|}{$\begin{array}{c}\text { Não-naturais } \\
\text { do Município }\end{array}$} & \multicolumn{2}{c|}{$\begin{array}{c}\text { Residência } \\
\text { Inferior a 10 anos }\end{array}$} & \multicolumn{2}{c|}{$\begin{array}{c}\text { Residência: } \\
10 \text { anos ou mais }\end{array}$} \\
\hline Censo & Homem & Mulher & Homem & Mulher & Homem & Mulher & Homem & Mulher & Homem & Mulher \\
\hline 1970 & 114.562 & 123.948 & 76.095 & 79.816 & 38.467 & 44.132 & 19.709 & 21.959 & 18.758 & 22.173 \\
\hline 1980 & 148.258 & 159.267 & 89.408 & 90.792 & 58.850 & 68.475 & 24.415 & 27.208 & 34.435 & 41.267 \\
\hline 1991 & 184.385 & 201.611 & - & - & - & - & - & - & - & - & - \\
\hline
\end{tabular}

Tabela 6b

Juiz de Fora: incremento demográfico e migração

\begin{tabular}{|c|c|c|c|c|c|c|c|}
\hline & Increm & dem & gráfico & & & & \\
\hline $\begin{array}{l}\text { Intervalos } \\
\text { Censitários }\end{array}$ & Total & Homens & Mulheres & $\begin{array}{c}\text { Por } \\
\text { migração }\end{array}$ & $\%$ & crescimento vegetativo & $\%$ \\
\hline $1960 / 1970$ & 69.070 & $\longrightarrow$ & $\longrightarrow$ & 41.668 & 60,3 & 27.402 & 39,7 \\
\hline $1970 / 1980$ & 69.015 & 33.696 & 35.319 & 51.623 & 74,8 & 17.392 & 25,2 \\
\hline $1980 / 1991$ & 78.471 & 36.127 & 42.344 & - & ----- & -. & --- \\
\hline
\end{tabular}

Fonte : FIBGE (1973, 1982, 1991)

Tabela 7

Composição da população de Juiz de Fora e migração

\begin{tabular}{|c|c|c|c|c|c|}
\hline $\begin{array}{c}\text { Censo } \\
\text { Demográfico }\end{array}$ & $\begin{array}{c}\text { População } \\
\text { Residente }\end{array}$ & $\begin{array}{c}\text { Naturais do } \\
\text { Município }\end{array}$ & $\%$ & Não-naturais do Município & $\%$ \\
\hline 1970 & 238.510 & 155.911 & 65,4 & 82.599 & 34,6 \\
\hline 1980 & 307.525 & 180.200 & 58,6 & 127.325 & 41,4 \\
\hline 1991 & 385.996 & & - & & - \\
\hline
\end{tabular}

Fonte : FIBGE $(1973,1982,1991)$ 


\section{Tabela 8}

População não-natural do município de Juiz de Fora / Censo 1970

\begin{tabular}{|l|r|r|r|}
\hline $\begin{array}{l}\text { Tempo de resid. } \\
\text { no Município }\end{array}$ & Homens & Mulheres & Totais \\
\hline menos de 1 ano & 3.559 & 3.780 & 7.339 \\
\hline 1 ano & 1.725 & 1.949 & 3.674 \\
\hline 2 anos & 2.723 & 3.002 & 5.725 \\
\hline 3 anos & 2.160 & 2.379 & 4.539 \\
\hline 4 anos & 1.646 & 1.888 & 3.534 \\
\hline 5 anos & 1.680 & 1.941 & 3.621 \\
\hline 6 a 10 anos & 6.216 & 7.020 & 13.236 \\
\hline 11 anos ou mais & 18.755 & 22.173 & 40.928 \\
\hline sem declaração & 3 & - & 3 \\
\hline Total & 38.467 & 44.132 & 82.599 \\
\hline Percentual & $46,6 \%$ & $53,4 \%$ & $100,0 \%$ \\
\hline
\end{tabular}

Fonte: FIBGE (1973: 403/405)

\section{Tabela 9}

População não-natural do município de Juiz de Fora / Censo 1980

\begin{tabular}{|l|c|c|r|}
\hline $\begin{array}{l}\text { Tempo de resid. } \\
\text { no Município }\end{array}$ & Homens & Mulheres & Totais \\
\hline menos de 1 ano & 4.219 & 4.653 & 8.872 \\
\hline 1 ano & 2.869 & 2.833 & 5.702 \\
\hline 2 anos & 3.214 & 3.444 & 6.658 \\
\hline 3 anos & 3.292 & 3.425 & 6.717 \\
\hline 4 anos & 2.555 & 2.790 & 5.345 \\
\hline 5 anos & 2.362 & 2.707 & 5.069 \\
\hline 6 a 9 anos & 5.904 & 7.356 & 13.260 \\
\hline 10 anos ou mais & 34.290 & 41.114 & 75.404 \\
\hline sem declaração & 145 & 153 & 298 \\
\hline Totais & 58.850 & 68.475 & 127.325 \\
\hline Percentuais & $46,2 \%$ & $53,8 \%$ & $100,0 \%$ \\
\hline
\end{tabular}

Fonte: FIBGE (1983: 485, 493, 501, 509, 517)

Tabela 10

População não-natural do município de Juiz de Fora, dos que migraram há menos de 10 anos, quanto à origem / Censo Demográfico 1980

\begin{tabular}{|l|r|}
\hline Procedências & Totais \\
\hline Minas Gerais & 37.365 \\
\hline Rio de Janeiro & 8.341 \\
\hline São Paulo & 2.489 \\
\hline Outros Locais/Sem declaração & 3.726 \\
\hline Total & 51.921 \\
\hline
\end{tabular}

Fonte : FIBGE (1983: 525, 533, 541, 549, 557)

Tabela 11

População não-natural do município de Juiz de Fora, quanto à procedência e sexo

\begin{tabular}{|l|l|l|l|l|r|r|r|r|r|r|}
\hline Censos & $\begin{array}{l}\text { População } \\
\text { Residente }\end{array}$ & $\begin{array}{c}\text { Naturais } \\
\text { Município }\end{array}$ & \multicolumn{3}{|c|}{ Não-naturais do Município } & \multicolumn{4}{c|}{ Procedência de zona } \\
\hline \multicolumn{3}{|c|}{} & Total & Homens & Mulheres & urbana & rural & s/declaração \\
\hline 1970 & 238.510 & 155.911 & 82.599 & 38.467 & 44.132 & 66.201 & 16.386 & 12 \\
\hline 1980 & 307.525 & 180.200 & 127.325 & 58.850 & 68.475 & 79.467 & 47.422 & 436 \\
\hline 1991 & 385.996 & - & - & - & - & - & - & - \\
\hline
\end{tabular}

Fonte : FIBGE (1973: 373) ; FIBGE(1982) 
Os dados apresentados nas tabelas anteriores ( $n . \circ 06, a$ e b, 07 e 11) mostram a expressiva importância quantitativa que a migração assume na configuração da população total do município. A tabela $n .{ }^{\circ} 06 \mathrm{~b}$ mostra que a participação relativa da migração na composição da população total de Juiz de Fora é muito expressiva quando comparada ao incremento demográfico total entre dois recenseamentos. Pelo tempo de residência no município (tabelas n.ำ 08 e 09), nota-se a expressiva mobilidade populacional na cidade. De acordo com o Censo Demográfico de 1980, $41,4 \%$ da população residente em Juiz de Fora não era natural do município, índice que foi aumentado quando comparado com o Censo Demográfico de 1970 (Tabela $n .^{\circ}$ 07). Uma análise mais detida em qualquer uma das tabelas apresentadas revela a grande importância de Juiz de Fora como pólo de atração regional.

O Censo Demográfico de 1980 mostrou dados relativos à origem dos migrantes (Tabela n. ${ }^{-10}$ ), o que confirma a teoria de que a maior parte dos que chegam são mineiros $e$, destacadamente, pode-se supor, vindos de cidades menores do "Sudeste" de Minas Gerais, que juntamente com parte do Estado do Rio de Janeiro (cidades próximas da divisa estadual) são locais fortemente polarizados por Juiz de Fora, seja pela busca de empregos, seja pela busca de seu terciário mais diversificado e desenvolvido (educação, comércio, prestação de serviços etc.).

Consubstanciando algumas idéias anteriores, nota-se que a maior parte dos que chegam a Juiz de Fora são mulheres (Tabelas 06, a e b, 08, 09 e 11), o que vai implicar (e explicar) uma maior participação desse sexo no conjunto total da população, embora, como já mencionado, o número de nascimentos masculinos seja maior.

De outro lado, a Tabela $n . \circ 11$ mostra que a maior parte dos migrantes, além de pertencerem ao sexo feminino, são procedentes em sua maioria de áreas urbanas, ou seja, de cidades ( provavelmente aquelas já citadas) sob a influência mais direta de Juiz de Fora. Esse fato torna-se ainda mais evidente quando se observam os dados sobre a população rural das outras cidades do Sudeste de Minas Gerais, especialmente aquelas que compõem a microregião de Juiz de Fora, onde se pode notar que as áreas rurais já não possuem um efetivo demográfico suficientemente grande para "exportar" suas populações e aumentar a participação relativa destas no total das migrações para Juiz de Fora. Ao contrário, esses mesmos municípios sofrem, antes, um translado de suas populações rurais para suas áreas urbanas, e daí sim, provavelmente, um salto para um centro maior : Juiz de Fora.

Segundo os diversos dados apresentados nas tabelas anteriores é possível tentar traçar o "perfil", pelo menos aproximado, do migrante que chega a Juiz de Fora : mulher, com idade superior a 14 anos, mineira e procedente de área urbana, provavelmente em busca de estudo, trabalho ou outros serviços presentes em Juiz de Fora (ausentes ou medíocres em sua cidade de origem) e que se fixa, destacadamente, na Área Urbana do Distrito Sede, na cidade propriamente dita, ajudando a compor o elevado índice de urbanização de Juiz de Fora.

Os "dados estatísticos do concurso vestibular" apresentados pela Universidade Federal de Juiz de Fora (UFJF) servem de importante exemplificação (e mesmo confirmação) da situação descrita no parágrafo anterior. Segundo o sexo, a idade e a procedência dos candidatos inscritos no concurso vestibular de 1996 e mesmo de outros anos, pode-se compreender o forte papel de centro polarizador regional exercido por Juiz de Fora e ainda reconhecer, em meio ao "perfil" do candidato a uma vaga nesta instituição, o próprio "perfil" do migrante que busca a cidade. As tabelas que se seguem foram extraídas do material divulgado pela 
UFJF, através da Coordenação Geral do Vestibular, e mostram dados relativos ao sexo, idade e procedência dos candidatos (e dos aprovados) no concurso vestibular.

\section{Tabela 12}

Candidatos segundo o sexo:

Concurso vestibular UFJF/1996

\begin{tabular}{|l|c|c|}
\hline Sexo & Inscritos & Aprovados \\
\hline Masculino & 7.499 & 741 \\
\hline Feminino & 10.791 & 833 \\
\hline Totais & 18.290 & 1.574 \\
\hline
\end{tabular}

Fonte: UFJF/CPD (1996: tabela 21)

Tabela $12 b$

Candidatos aprovados nos concursos vestibulares de 1993, 1994, 1995 e 1996, na UFJF, segundo o sexo

\begin{tabular}{|c|c|c|c|c|}
\hline anos & Homens & $\%$ & Mulheres & $\%$ \\
\hline 1993 & 621 & 43,67 & 801 & 56,33 \\
\hline 1994 & 567 & 44,93 & 695 & 55,07 \\
\hline 1995 & 501 & 43,19 & 659 & 56,81 \\
\hline 1996 & 741 & 47,08 & 833 & 52,92 \\
\hline
\end{tabular}

Fonte: UFJF/CPD (1996: tabela 47)

\section{Tabela 13}

Candidatos segundo a idade: Concurso Vestibular UFJF/1996

\begin{tabular}{|l|c|c|}
\hline Faixas etárias & Inscritos & Aprovados \\
\hline até 17 anos & 3.407 & 256 \\
\hline 18 anos & 5.263 & 404 \\
\hline 19 anos & 3.517 & 303 \\
\hline 20 a 24 anos & 4.670 & 419 \\
\hline 25 a 29 anos & 712 & 83 \\
\hline 30 anos e mais & 520 & 88 \\
\hline Em branco ( $\left.{ }^{*}\right)$ & 201 & 11 \\
\hline Totais & 18.290 & 1.574 \\
\hline
\end{tabular}

(*) Candidatos que não responderam ao questionário da UFJF Fonte: UFJF/CPD (1996: Tabela 22)
Tabela 13b

Candidatos aprovados nos Concursos Vestibulares

de 1995 e 1996, na UFJF, segundo a idade

\begin{tabular}{|l|r|r|r|c|}
\hline Faixas Etárias & 1995 & \multicolumn{1}{|c|}{$\%$} & 1996 & $\%$ \\
\hline 17 anos & 156 & 9,94 & 256 & 16,26 \\
\hline 18 anos & 298 & 18,99 & 404 & 25,67 \\
\hline 19 anos & 235 & 14,98 & 313 & 18,89 \\
\hline 20 a 24 anos & 328 & 20,91 & 419 & 26,62 \\
\hline 25 a 29 anos & 86 & 5,48 & 83 & 5,27 \\
\hline 30 anos e mais & 47 & 3,00 & 88 & 5,59 \\
\hline Em Branco $\left(^{*}\right)$ & 419 & 26,70 & 11 & 0,70 \\
\hline Totais & 1.569 & 100,00 & 1.574 & 100,00 \\
\hline
\end{tabular}

Fonte: UFJF/CPD (1996: Tabela 45)

$\left.{ }^{*}\right)$ Candidatos que não responderam ao questionário da UJFJ.

Tabela 14

Residência atual dos candidatos ao Vestibular UFJF/1996

\begin{tabular}{|l|c|c|}
\hline Locais & Inscritos & Aprovados \\
\hline Juiz de Fora & 6.460 & 944 \\
\hline Belo Horizonte & 1.659 & 85 \\
\hline Interior de MG & 4.688 & 304 \\
\hline outros estados & 5.260 & 225 \\
\hline outro país & 30 & 4 \\
\hline Em branco & 193 & 12 \\
\hline Totais & 18.290 & 1.574 \\
\hline
\end{tabular}

Fonte: UFJF/CPD (1996: Tabela 26)

(*)Candidatos que não responderam ao questionário da UFJF

Deve-se ressaltar aqui que a migração, tratada como importante elemento contributivo do crescimento demográfico de Juiz de Fora, só foi analisada quantitativamente em seu aspecto permanente, ou seja, só foi levado em consideração o número de transferências populacionais ocorridas para a cidade em caráter definitivo. A outra parte do sistema migratório, a migração pendular, diária, que resulta na população flutuante do município, não foi aqui considerada, por simples ausência de dados oficiais. Não obstante, o estudo desse processo é de fundamental importância 
para a melhor compreensão da dinâmica demográfica urbana de Juiz de Fora, quer seja por suas implicações econômicas (empregos, serviços, comércio etc.), quer seja por suas demandas em infra-estrutura urbana básica (transportes, educação, serviços públicos etc.).

\section{OS ÍNDICES DE CRESCIMENTO}

Pelos dados da tabela $n . .15$, observase a desaceleração do ritmo de crescimento demográfico de Juiz de Fora. Desde o decênio 1950/1960, a taxa de crescimento médio anual vem diminuindo de forma constante até o Censo de 1991. Essa diminuição no ritmo do crescimento populacional em Juiz de Fora pode ser atribuída, dentre outras causas, à redução substancial da taxa de natalidade, ocorrida paralelamente ao envelhecimento da população (maior esperança de vida, conforme dados apresentados na tabela n. ${ }^{\circ} 01$ ). Isso significa famílias menores, com uma menor relação mulher/número de filhos. De outro lado, e como já discutido anteriormente, a migração passou a significar um importante elemento na determinação do crescimento demográfico da cidade. Mas, se de um lado a imigração ("chegada") continua com índices elevados e a taxa de crescimento demográfico continua baixando, o que ocorre, provavelmente, é um paralelo e igualmente significativo índice de emigração ("saída"), o que faz com que a migração tenha seu impacto amortecido no conjunto total do crescimento demográfico.

Tabela 15

Taxa de crescimento médio anual da População Residente de Juiz de Fora

\begin{tabular}{|l|c|c|c|c|}
\hline Períodos & $1950 / 1960$ & $1960 / 1970$ & $1970 / 1980$ & $1980 / 1991$ \\
\hline Taxas & $3,99 \%$ & $3,48 \%$ & $2,57 \%$ & $2,08 \%$ \\
\hline
\end{tabular}

Mesmo crescendo num ritmo mais lento

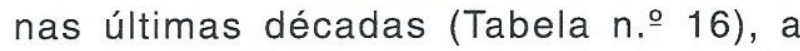
participação relativa da população de Juiz de Fora em relação à população total do Estado de Minas Gerais vem aumentando, o que não ocorre com os índices participativos de sua microregião (Microregião de Juiz de Fora) que, formada por 31 municípios vem, desde o Censo de 1960, mantendo-se estável, em torno dos $3,7 \%$ de participação na população total do Estado. Aqui se pode notar que o ritmo de crescimento de Juiz de Fora é bem superior ao de sua microregião, o que se deve, basicamente, ao destacado processo migratório que ocorre entre esses municípios e aquele pólo regional.

Tabela 16

Participação relativa da População Residente de Juiz de Fora

\begin{tabular}{|l|r|r|r|r|r|r|r|r|}
\hline & \multicolumn{2}{|c|}{1960} & \multicolumn{2}{c|}{1970} & \multicolumn{2}{c|}{1980} & \multicolumn{2}{c|}{1991} \\
\hline Áreas & Pop. & \multicolumn{1}{c|}{$\%$} & \multicolumn{1}{c|}{ Pop. } & \multicolumn{1}{c|}{$\%$} & \multicolumn{1}{c|}{ Pop. } & \multicolumn{1}{c|}{$\%$} & Pop. & $\%$ \\
\hline M.Gerais & 9.657 .738 & 100,00 & 11.487 .415 & 100,00 & 13.380 .105 & 100,00 & 15.743 .152 & 100,00 \\
\hline Micro JF & 364.736 & 3,78 & 433.038 & 3,77 & 494.331 & 3,69 & 583.118 & 3,70 \\
\hline J. de Fora & 169.440 & 1,75 & 238.510 & 2,07 & 307.525 & 2,30 & 385.996 & 2,45 \\
\hline
\end{tabular}

Fonte: FIBGE $(1973,1982,1991)$ 
Tabela 17

Microregião de Juiz de Fora : evolução da População residente

\begin{tabular}{|c|c|c|c|c|c|}
\hline Municípios & $\begin{array}{c}\text { Censo } \\
1950 \\
\end{array}$ & $\begin{array}{c}\text { Censo } \\
1960\end{array}$ & $\begin{array}{c}\text { Censo } \\
1970 \\
\end{array}$ & $\begin{array}{c}\text { Censo } \\
1980\end{array}$ & $\begin{array}{c}\text { Censo } \\
1991\end{array}$ \\
\hline Aracitaba & 2.504 & 3.340 & 2.825 & 2.665 & 2.400 \\
\hline Belmiro Braga & 6.649 & 5.745 & 5.328 & 3.933 & 3.975 \\
\hline Bias Fortes & 5.031 & 5.754 & 5.591 & 5.043 & 4.852 \\
\hline Bicas & 8.157 & 10.102 & 10.389 & 10.336 & 11.239 \\
\hline Chácara & 2.522 & 2.659 & 3.514 & 3.057 & 3.257 \\
\hline Chiador & 7.117 & 6.617 & 4.735 & 3.899 & 2.900 \\
\hline Coronel Pacheco & 3.252 & 4.637 & 3.925 & 3.300 & 3.252 \\
\hline Descoberto & 4.428 & 4.851 & 4.464 & 3.899 & 4.083 \\
\hline Ewbanck da Câmara & 2.395 & 2.886 & 3.294 & 2.986 & 3.286 \\
\hline Guarará & 2.956 & 3.088 & 2.868 & 2.839 & 3.814 \\
\hline JUIZDE FORA & 114.531 & 169.440 & 238.510 & 307.525 & 385.996 \\
\hline Lima Duarte & 14.651 & 13.771 & 14.578 & 14.313 & 14.641 \\
\hline Mar de Espanha & 9.273 & 9.713 & 8.901 & 7.907 & 9.710 \\
\hline Maripá de Minas & 2.579 & 2.367 & 2.361 & 2.237 & 2.287 \\
\hline Matias Barbosa & 5.740 & 7.269 & 8.788 & 9.404 & 10.955 \\
\hline Olaria & 2.575 & 2.151 & 2.508 & 2.221 & 2.283 \\
\hline Oliveira Fortes & 2.543 & 3.330 & 2.866 & 2.178 & 2.183 \\
\hline Paiva & 1.940 & 2.218 & 2.143 & 1.653 & 1.416 \\
\hline Pedro Teixeira & 1.760 & 1.733 & 1.802 & 1.541 & 1.593 \\
\hline Pequeri & 2.057 & 2.332 & 2.701 & 2.683 & 2.716 \\
\hline Piau & 4.358 & 4.619 & 3.931 & 3.430 & 3.023 \\
\hline Rio Novo & 10.428 & 11.645 & 11.039 & 9.591 & 11.179 \\
\hline Rio Preto & 9.492 & 9.424 & 9.034 & 8.275 & 7.271 \\
\hline Rochedo de Minas & 2.476 & 2.031 & 1.825 & 1.513 & 1.546 \\
\hline Santana do Deserto & 3.635 & 3.938 & 3.593 & 3.265 & 3.417 \\
\hline Santa Rita de Ibitipoca & 4.299 & 5.361 & 5.050 & 5.365 & 4.064 \\
\hline Santa Rita do Jacutinga & 6.227 & 7.016 & 5.408 & 7.534 & 5.122 \\
\hline Santos Dumont & 28.511 & 34.401 & 37.985 & 40.005 & 44.965 \\
\hline São João Nepomuceno & 15.803 & 17.063 & 18.156 & 17.611 & 21.432 \\
\hline Senador Cortes & 2.993 & 2.494 & 2.096 & 1.754 & 1.847 \\
\hline Simão Pereira & 3.257 & 2.741 & 2.830 & 2.369 & 2.414 \\
\hline Totais & 294.139 & 364.736 & 433.038 & 494.331 & 583.118 \\
\hline
\end{tabular}

Fonte : $\operatorname{FIBGE}(1973,1983,1991)$

Uma comparação entre os índices de crescimento da população de Juiz de Fora e de sua microregião mostra bem o aspecto de concentração da população regional em Juiz de Fora. Entre 1980 e 1991, a população da microregião de Juiz de Fora (31 municípios) foi acrescida em 88.787 habitantes. No entanto só o aumento, no mesmo período, da
Tabela 18

Crescimento demográfico de Juiz de Fora e sua microregião no período 1980/1991

\begin{tabular}{|l|c|c|c|c|}
\hline Área de análise & Pop. 1980 & Pop. 1991 & Crescim. & $\%$ \\
\hline Microregião J.Fora & 494.331 & 583.118 & +88.787 & 100,00 \\
\hline Juiz de Fora & 307.525 & 385.996 & +78.471 & 88,38 \\
\hline
\end{tabular}


população da cidade de Juiz de Fora, foi de 78.471 pessoas, ou seja, $88,38 \%$ de todo o crescimento demográfico da microregião.

Os dados da tabela n. $\circ 17$ são bastante explicativos e confirmam esta situação colocada anteriormente. A maior parte dos municípios da microregião de Juiz de Fora vem, historicamente, sofrendo um processo de diminuição sensível de suas populações. Poucos são aqueles que conseguiram aumentar sua população no último intervalo censitário. O que ocorre, na verdade, é que estes municípios mal conseguem "repor" suas populações "perdidas" para o "Core" regional (Juiz de Fora). São, em sua maioria, "cidadesdormitórios" que vêm sofrendo um processo de rápido envelhecimento de suas populações, principalmente em função do processo migratório para Juiz de Fora, que via de regra é praticado pela parcela da população em idade "jovem", destacadamente para conclusão ou aprofundamento escolar. Este efeito já não é tão característico no deslocamento de mãode-obra dessas cidades para Juiz de Fora. Nesse caso específico, em geral, não ocorre a migração definitiva, mas um constante movimento pendular diário entre tais cidades.

\section{ALGUMAS PROJEÇÕES}

As projeções de população oficiais feitas para a cidade (FIBGE) têm levado em consideração taxas de crescimento menores que os atuais $2,08 \%$ ao ano, como registrado no último Censo Demográfico. Não se levando em conta nenhum novo fenômeno (econômico ou demográfico), pode-se estimar a população total de Juiz de Fora, ou mantendo-se essa última taxa de crescimento anual, ou projetando-se o seu declínio futuro, como aliás vem ocorrendo nas últimas décadas.

Mesmo sabendo-se das dificuldades e dos graves inconvenientes de se tentar fazer qualquer tipo de prognóstico para o crescimento populacional de um lugar qualquer, buscamos criar três situações de ritmo de crescimento, para projetar, até o ano 2000, a população total de Juiz de Fora.

\section{A) Situação 01 - Mantendo-se a mesma taxa de crescimento anual de $2,08 \%$}

\begin{tabular}{|c|c|}
\hline anos & População projetada \\
\hline 1991 & 385.996 (Censo) \\
\hline 1992 & 394.025 \\
\hline 1993 & 402.220 \\
\hline 1994 & 410.587 \\
\hline 1995 & 419.127 \\
\hline 1996 & 427.845 \\
\hline 1997 & 436.744 \\
\hline 1998 & 445.828 \\
\hline 1999 & 455.101 \\
\hline 2000 & 464.567 \\
\hline
\end{tabular}

B) Situação 02 - Partindo-se da última taxa oficial de crescimento anual registrada $(2,08 \%)$ e reduzindo-a, anualmente, conforme o decréscimo médio anual ocorrido nos últimos 11 anos (1980/1991)

\begin{tabular}{|l|ll|}
\hline anos & \multicolumn{3}{|c|}{ População projetada } \\
\hline 1991 & 385.996 & $(2,08 \%)$ - Censo \\
\hline 1992 & $393.851 \quad(2,035 \%)$ \\
\hline 1993 & 401.689 & $(1,990 \%)$ \\
\hline 1994 & 409.506 & $(1,946 \%)$ \\
\hline 1995 & 417.294 & $(1,902 \%)$ \\
\hline 1996 & 425.043 & $(1,857 \%)$ \\
\hline 1997 & $432.750 \quad(1,813 \%)$ \\
\hline 1998 & 440.401 & $(1,768 \%)$ \\
\hline 1999 & $447.993 \quad(1,724 \%)$ \\
\hline 2000 & $455.515 \quad(1,679 \%)$ \\
\hline
\end{tabular}


C) Situação 03 - Partindo-se do decréscimo decenal registrado nos últimos três intervalos censitários, têm-se um índice projetado para o período 1991/2000

\begin{tabular}{|l|l|}
\hline Intervalo Censitário & Taxa de crescimento \\
\hline $1960 / 1970$ & $3,48 \%$ \\
\hline $1970 / 1980$ & $2,57 \%$ \\
\hline $1980 / 1991$ & $2,08 \%$ \\
\hline $1991 / 2000$ & $1,76 \%$ (estimativa) \\
\hline
\end{tabular}

\begin{tabular}{|l|c|}
\hline anos & População Projetada \\
\hline 1991 & 385.996 (Censo) \\
\hline 1992 & 392.790 \\
\hline $1993\left(^{\star}\right)$ & 399.703 \\
\hline 1994 & 406.737 \\
\hline 1995 & 413.896 \\
\hline 1996 & 421.181 \\
\hline 1997 & 428.593 \\
\hline 1998 & 436.137 \\
\hline 1999 & 443.813 \\
\hline 2000 & 451.623 \\
\hline
\end{tabular}

(*) Lembramos aqui, para efeito de avaliação e comparação dos índices adotados anteriormente que, segundo a projeção oficial do IBGE, a população estimada de Juiz de Fora, em 1993, era de 399.327 habitantes, o que mostra ser um dado muito próximo daquele obtido (sugerido ou projetado) na situação 03 desse estudo.

\section{UM CENÁRIO DE PROVÁVEL DESENVOLVIMENTO E CONSOLIDAÇÃO INDUSTRIAL}

Já há alguns anos, um dos temas mais debatidos e mais destacados na mídia e na política local, é o preocupante estado de 'decadência econômica da região', quase invariavelmente acompanhado pelo discurso, geralmente político, da 'retomada do desenvolvimento regional'. Porém, a reflexão sobre a superação da atual situação econômica da Zona da Mata Mineira vem atendo-se, ao longo do tempo, exclusivamente sobre propostas baseadas no desenvolvimento da atividade industrial e, logicamente, por conseqüência, soluções são buscadas unicamente em atividades econômicas próprias do meio urbano, especialmente a industrialização.

Os efeitos dessa longa crise econômica regional e em especial na microregião de Juiz de Fora, composta por 31 municípios, tem causas históricas múltiplas. Porém, deve ser destacado aqui que a década de 1990 tem se mostrado muito promissora ao processo de industrialização e conseqüente (re)desenvolvimento da região, o que ocorreu através do desencadeamento de alguns eventos importantes, infra-estruturais e finais, que acabaram por render expectativas entusiasmadas para o futuro de Juiz de Fora e sua região.

A passagem do gasoduto, insumo primário do processo industrial, pelos limites da cidade (Campos - Juiz de Fora - Belo Horizonte), serviu de importante motor nesse novo processo de industrialização, mas foi com o anúncio oficial da instalação de uma fábrica de automóveis (Mercedes Benz) em Juiz de Fora, após uma severa concorrência com outras cidades do País, que a tão buscada 'retomada do desenvolvimento econômico regional' passou a ser sentida de forma mais próxima.

Dentre os vários impactos, positivos e negativos, que a instalação dessa montadora (e suas várias indústrias satélites) vai trazer para a cidade e região, alguns se tornam bastante difíceis de serem calculados ou projetados. No caso específico do crescimento populacional da cidade, poucos elementos se tem para projetar as conseqüências que se darão sobre a dinâmica demográfica local (processos de migração definitiva e/ou pendular; alteração nas atuais taxas de crescimento demográfico; mudanças no tamanho médio das famílias etc.). O fato concreto é que o atual ritmo de crescimento deverá ser alterado, muito embora seja difícil afirmar-se o quantitativo dessa transformação. 
Por certo, durante alguns anos, as taxas de crescimento demográfico deverão aumentar sensivelmente em relação àquelas que vêm sendo registradas nos últimos Censos Demográficos. Mudança que se dará muito mais em função de um destacado processo migratório do que por um substancial aumento nas taxas de crescimento vegetativo. Mesmo sendo difícil fazer-se projeções seguras, em função dessas novas realidades, por certo todas as estimativas de crescimento demográfico para o futuro da região e especialmente de Juiz de Fora deverão ser refeitas, como aquelas anunciadas no item 5 deste trabalho, que levam em consideração apenas aspectos demográficos historicamente observados ao longo dos últimos censos.

Um aspecto que não deve ser negligenciado, em hipótese alguma, é que um dos elementos mais importantes para a escolha de Juiz de Fora pela Mercedes Benz foi exatamente os seus indicadores positivos de infra-estrutura urbana e de qualidade de vida. Longe de serem ideais, os atuais índices urbanos em Juiz de Fora são positivamente muito significativos, refletindo uma situação de bom atendimento às demandas básicas por serviços públicos pela população. Lógico que esta situação poderá ser drasticamente alterada, caso passe a ocorrer em Juiz de Fora o mesmo modelo de desenvolvimento concentrador que estamos acostumados a ter como exemplo em todas as partes do país. Em geral, as demandas pelos serviços de infraestrutura básica crescem num ritmo maior que aquele que o Poder Público Municipal tem de capacitar-se a atendê-los. Porisso a importância de se pensar, desde já, num processo de industrialização realmente regional e descentralizado, que evite uma concentração excessiva no 'core' Juiz de Fora.

A trama urbano-regional que envolve Juiz de Fora é muito complexa e particular e não pode ser pensada de forma separada, sob o risco de vermos definhar, definitivamente, boa parte dos municípios de sua microregião (historicamente, estoques de mão-de-obra e de boas e tranqüilas áreas para o lazer) e de outro lado, acompanharmos o "inchaço" urbano demasiado do pólo regional. Ou se pensa em dividir as benesses do desenvolvimento ou se terá que remediar os inconvenientes problemas sociais inevitáveis e inerentes à concentração da pobreza na cidade-pólo. O nosso modelo de desenvolvimento industrial, concentrador (tanto de renda quanto espacialmente), nos mostra, através de inúmeros exemplos, que quanto maior o crescimento econômico de um lugar, maiores também são as carências e a pobreza. O que comumente vemos é que crescimento econômico não significa obrigatoriamente melhor qualidade de vida, pelo menos não para a maioria da população. Em geral, no país, crescimento econômico não vem sendo sinônimo de desenvolvimento social.

\section{7. ÍNDICES DE INFRA-ESTRUTURA URBANA BÁSICA E DE ALFABETIZAÇÃO}

Tabela 19

Juiz de Fora : índices de alfabetização das pessoas com 5 anos de idade ou mais

\begin{tabular}{|c|c|c|c|}
\hline Censos & Pop.Residente $\left({ }^{*}\right)$ & Alfabetizados & $\%$ \\
\hline 1970 & 211.425 & 160.387 & 75,8 \\
\hline 1980 & 275.497 & 234.646 & 85,2 \\
\hline 1991 & 350.109 & 311.040 & 88,8 \\
\hline
\end{tabular}

(*) inclui todos os grupos etários, exceto o grupo de 0 a 4 anos de idade.

Fonte: FIBGE (1970, 1980 e 1991). 
Tabela 20

Juiz de Fora: Índices de alfabetização das pessoas com 5 anos de idade ou mais, por Distritos, nos Censos Demográficos de 1980 e 1991

\begin{tabular}{|c|c|c|c|c|c|c|}
\hline Unidades & Pop. $1980\left(^{*}\right)$ & Alfabetizados & $\%$ & Pop. $1991\left(^{*}\right)$ & Alfabetizados & $\%$ \\
\hline Juiz de Fora & 275,497 & 234.646 & 85.17 & 350.109 & 311.040 & 88.84 \\
\hline urbano & 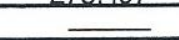 & 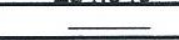 & 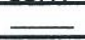 & 344.960 & 307.539 & 89.15 \\
\hline rural & $\bar{L}$ & $\overline{\bar{L}}$ & $\overline{-}$ & 5.149 & 3.501 & 67.99 \\
\hline Distrito Sede & 270.294 & 231.460 & 85.63 & 344.709 & 307.155 & 89.10 \\
\hline urbano & 268.427 & 230.378 & 85.82 & 342.748 & 305.896 & 89.24 \\
\hline rural & 1.867 & 1.082 & 57.95 & 1.961 & 1.259 & 64.20 \\
\hline Rosário de Minas & 1.846 & 1.092 & 59.15 & 2.014 & 1.519 & 75.42 \\
\hline urbano & 824 & 545 & 66.14 & 1.078 & 857 & 79.49 \\
\hline rural & 1.022 & 547 & 53.52 & 936 & 662 & 70.72 \\
\hline Sarandira & 1.054 & 624 & 59.20 & 925 & 604 & 65.29 \\
\hline urbano & 596 & 391 & 65.60 & 478 & 319 & 66.73 \\
\hline rural & 458 & 233 & 50.87 & 447 & 285 & 63.75 \\
\hline Torreões & 2.303 & 1.470 & 63.82 & 2.461 & 1.762 & 71.59 \\
\hline urbano & 559 & 396 & 70.84 & 656 & 467 & 71.18 \\
\hline rural & 1.744 & 1.074 & 61.58 & 1.805 & 1.295 & 71.74 \\
\hline
\end{tabular}

(*) Inclui todos os grupos etários, exceto o grupo de 0 a 4 anos de idade;

Fonte: FIBGE $(1982,1991)$

Os índices de alfabetização apontam para percentuais elevados e crescentes ao longo das últimas décadas, em todas as unidades administrativas do município. Em contrapartida, há uma destacada concentração desses índices mais elevados no Distrito Sede e, em especial, nas áreas urbanas de todos os Distritos. De 1980 para 1991, todos os índices percentuais tiveram aumento, o que pode atestar um aumento da abrangência das redes de ensino no município, com conseqüente atendimento das demandas por vagas nas escolas.
Igualmente elevados e crescentes são os índices de todos os serviços infra-estruturais urbanos básicos (tabela n. 21), que conseguiram aumentar $o$ índice de atendimento num ritmo maior que o crescimento da demanda (População Residente). Aqui, por falta de dados para consulta, não se conseguiu analisar a distribuição sócio-espacial dos atendimentos desses serviços, mas por certo, concorre à existência de áreas muito bem servidas, outras com precários serviços ou mesmo com ausência destes.

Tabela 21

Juiz de Fora : serviços básicos de infra-estrutura urbana

\begin{tabular}{|c|c|c|c|c|c|c|c|}
\hline Censos & $\begin{array}{c}\text { Domicílios } \\
\text { Ocupados }\end{array}$ & Água & $\%$ & $\begin{array}{c}\text { Instalação } \\
\text { Sanitária }\end{array}$ & $\%$ & $\begin{array}{c}\text { Lixo } \\
\text { Coletado }\end{array}$ & \begin{tabular}{c}
$\%$ \\
\hline 1970
\end{tabular} \\
\hline 44.866 & 29.440 & 65,6 & 26.453 & 58,9 & - & - \\
\hline 1980 & 69.096 & 51.526 & 74,6 & 50.255 & 72,7 & - & - \\
\hline 1991 & 100.498 & 92.316 & 91,9 & 88.659 & 88,2 & 91.247 & 90,8 \\
\hline
\end{tabular}

Fonte: FIBGE $(1973,1982,1991)$

Obs.: Os dados relativos ao abastecimento de água e de instalação sanitária relacionam-se às ligações da rede geral.

Cumpre aqui destacar que, embora estes índices percentuais de atendimento sejam bastante elevados, eles são uma referência dos Censos Demográficos do IBGE, valendo dizer que os índices atuais, divulgados pela Prefeitura de Juiz de Fora, através de seus órgãos específicos (CESAMA e DEMLURB), dão conta de números percentuais ainda 
maiores, mostrando que a situação atual acerca dos serviços oferecidos pelo Poder Público Municipal pode ser considerada, no mínimo, satisfatória, bem acima das médias nacionais. Os serviços de abastecimento de água, ligações de rede de esgoto e recolhimento de lixo, em todos os casos, atingem percentuais superiores a $90 \%$ de atendimento. Por mais uma vez deve-se observar que a demanda por estes serviços vem aumentando (e tende a aumentar ainda mais com a nova realidade industrial da cidade), numa velocidade bastante elevada, por vezes superior às possibilidades que as Administrações Municipais têm de oferecê-los.

Importante que se discuta aqui que esses dados referem-se apenas ao atendimento das demandas básicas da população, não se refletindo obrigatoriamente em "qualidade de vida", modelo ou padrão. Se levarmos em consideração as questões ambientais mais amplas e atuais que envolvem esta discussão e que estão diretamente relacionadas aos parâmetros de qualidade de vida, teremos que discutir não só o atendimento ou o abastecimento, mas igualmente todo o ciclo que o envolve. Assim, discutir o próprio conceito atual (e mais amplo) de infra-estrutura urbana básica e de qualidade de vida, numa perspectiva de contrapor o quantitativo e o qualitativo. Assim, não só preocupar-se com o número percentual que simboliza o recolhimento de lixo diariamente, mas discutir a sua destinação final, aspecto tão complicado em Juiz de Fora, quer seja pela situação do atual "aterro sanitário" , localizado noutro município limítrofe, quer seja pela dificuldade de alocar áreas propícias para um futuro aterro sanitário, isto sem mencionar o fato de que uma "sociedade do descartável" como é a nossa, ser, por si só, uma geradora potencial de maior quantidade diária de 'lixo', que quando não reciclado, como ainda ocorre na maior parte das vezes, passa a requerer mais áreas para sua deposição final ; de igual forma, não só mostrar índices positivos referentes à rede de esgoto, mas discutir e buscar formas alternativas para seu tratamento e assim evitar que o Rio Paraibuna pague o elevado custo ambiental de ter se transformado no maior canal de esgotos da cidade ; ou ainda pensar que a grande questão talvez não seja simplesmente criar novas adutoras para o abastecimento d'água à população, mesmo sendo este um importante passo para sua distribuição, mas de outro lado, pensar a água como um insumo vital e renovável somente dentro de certos limites, necessitando-se para tanto de um trabalho eficaz de conservação e uso racional das áreas de seus mananciais (ocupação, tipos de usos, zoneamentos, reflorestamento etc.), que são, em última análise, os grandes responsáveis pela sua maior quantidade e melhor qualidade.

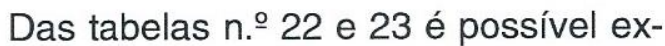
trairem-se duas observações bastante claras. Tanto a relação morador/domicílio quanto o tamanho médio das famílias de Juiz de Fora sofreu uma sensível redução ao longo desses últimos anos. Especificamente sobre o tama-

Tabela 22

Juiz de Fora: domicílios (*) e pessoas moradoras

\begin{tabular}{|c|c|c|c|c|c|}
\hline Censos & $\begin{array}{c}\text { Domicílios } \\
\text { Ocupados }\end{array}$ & $\begin{array}{c}\text { Pessoas } \\
\text { moradoras }\end{array}$ & $\begin{array}{c}\text { Morador/ } \\
\text { domicílio }\end{array}$ & $\begin{array}{c}\text { Domicílio } \\
\text { próprio }\end{array}$ & $\begin{array}{c}\text { Domicílio } \\
\text { alugado }\end{array}$ \\
\hline 1970 & 44.866 & 231.616 & 5,16 & - & - \\
\hline 1980 & 69.096 & 303.719 & 4,40 & 36.198 & 26.070 \\
\hline 1991 & 100.498 & 381.997 & 3,80 & - & - \\
\hline
\end{tabular}

(*) Dados relativos aos domicílios particulares permanentes Fonte: FIBGE (1973, 1982, 1991) 
Tabela 23

Juiz de Fora: domicílios, número de famílias e chefes de família

\begin{tabular}{|c|c|c|c|c|c|}
\hline Censos & Pessoas & Famílias & Média & \multicolumn{2}{|c|}{ Chefes de Família } \\
\hline Demográficos & Residentes & & Familiar & Homens & Mulheres \\
\hline 1970 & 231.616 & 48.011 & 4,82 & 40.202 & 7.809 \\
\hline 1980 & 303.719 & 73.968 & 4,10 & 59.204 & 14.764 \\
\hline 1991 & 381.997 & 100.785 & 3,79 & 77.676 & 23.109 \\
\hline
\end{tabular}

Fonte: FIBGE $(1973,1982,1991)$

nho das famílias, tal redução já era esperada, tendo em vista os dados demográficos anteriormente apresentados e que apontavam para uma redução no número de nascimentos. Uma outra observação a ser feita, pelos dados dessas tabelas, refere-se ao aumento relativo do número de mulheres como chefes de família, refletindo uma tendência já confirmada de forma mais ampla nos dados referentes ao país.
A tabela $n . \circ 24$ mostra a distribuição dos domicílios, em 1991, pelos Distritos do município. Além da forte concentração no Distrito Sede, tal qual acontece com a população, pode-se notar uma maior média de ocupação dos domicílios nos Distritos "mais rurais", o que certamente reflete, ainda, a existência de famílias maiores.

Tabela 24

Juiz de Fora: número de domicílios e pessoas moradoras, por Distritos, segundo o Censo Demográfico de 1991

\begin{tabular}{|l|c|c|c|}
\hline $\begin{array}{c}\text { Unidades } \\
\text { Administrativas }\end{array}$ & $\begin{array}{c}\text { Domicílios } \\
\text { Ocupados }\end{array}$ & $\begin{array}{c}\text { Pessoas } \\
\text { Moradoras }\end{array}$ & $\begin{array}{c}\text { Média } \\
\text { Domicílio }\end{array}$ \\
\hline Juiz de Fora (Município) & 100.498 & 381.997 & 3,80 \\
\hline Distrito Sede & 99.042 & 375.997 & 3,80 \\
\hline Rosário de Minas & 503 & 2.238 & 4,45 \\
\hline Sarandira & 239 & 1.020 & 4,27 \\
\hline Torreões & 714 & 2.742 & 3,84 \\
\hline
\end{tabular}

Fonte: FIBGE (1991)

\section{BIBLIOGRAFIA}

FIBGE. Censo Demográfico - Minas Gerais: VIII Recenseamento Geral - 1970. Rio de Janeiro. FIBGE. 1973. Vol. I, Tomo XIV, $2^{\mathrm{a}}$ parte.

FIBGE. Censo Demográfico - dados distritais Minas Gerais: IX Recenseamento Geral do Brasil - 1980. Rio de Janeiro. FIBGE. 1982. Vol.1, Tomo 3, n.ำ 14.
FIBGE. Censo Demográfico: IX Recenseamento Geral do Brasil - 1980. Rio de Janeiro. FIBGE. 1983. Vol.1, Tomo 4, n. 16.

FIBGE. Censo Demográfico 1991 - Resultados do universo da população e dos domicílios. Rio de Janeiro. FIBGE. 1991. N.ำ 18. Minas Gerais.

UFJF. Dados estatísticos do Concurso Vestibular/UFJF. Juiz de Fora. UFJF. 1996. 